\title{
DESENVOLVIMENTO MORFOLÓGICO DAS GRAMAS ESMERALDA, SÃO CARLOS E TIFTON 419
}

\author{
Morphological development of Emerald, Carpetgrass and Tifton 419 turfgrasses
}

\author{
Cleusa Maria Kojoroski-Silva1, Simone Meredith Scheffer-Basso ${ }^{2}$, Cerci Maria Carneiro², Maurício Guarienti ${ }^{2}$
}

\begin{abstract}
RESUMO
Avaliou-se o desenvolvimento morfológico das gramas São Carlos (Axonopus affinis), Tifton 419 (Cynodon dactylon $\mathrm{x}$ C. transvaalensis) e Esmeralda (Zoysia sp.), cultivadas em casa de vegetação e colhidas integralmente aos 97, 118, 146, 174, 202, 230 e 258 dias de idade. A Tifton 419 mostrou os maiores comprimentos de estolão $(83,3 \mathrm{~cm})$, altura de planta $(23,6 \mathrm{~cm})$ e número de folhas (12-24 $\mathrm{cm}^{-1}$ de estolão); as folhas mediram 6,7 cm x 1,9 mm (textura fina). Os estolões da São Carlos atingiram em média $58,3 \mathrm{~cm}$ e foram os mais espessos $(2,5 \mathrm{~cm})$, com 2-4 folhas $\mathrm{cm}$ de estolão ${ }^{-1}$; as folhas mediram 10,9 $\mathrm{cm} \mathrm{x} \mathrm{12,3} \mathrm{mm} \mathrm{(textura} \mathrm{grossa)} \mathrm{e} \mathrm{a} \mathrm{altura}$ máxima da planta foi de $13 \mathrm{~cm}$. A Esmeralda foi inferior quanto à altura $(10 \mathrm{~cm})$, comprimento de estolão $(45 \mathrm{~cm})$ e número de folhas ( 7 folhas $\mathrm{cm}$ de estolão ${ }^{-1}$ ); as folhas mediram $6,2 \mathrm{~cm} \mathrm{x} \mathrm{3,7} \mathrm{mm} \mathrm{(textura} \mathrm{média).} \mathrm{O}$ acúmulo de matéria seca da parte aérea (mg planta ${ }^{-1}$ ) atingiu 12.100 (São Carlos), 8.700 (Tifton 419) e 3.500 (Esmeralda) e a relação raiz:parte aérea foi de 0,$33 ; 0,15$ e 0,19 , respectivamente. As distintas características morfológicas das gramas podem subsidiar sua escolha para diferentes propósitos.
\end{abstract}

Termos para indexação: Axonopus, Cynodon, Zoyzia, estolão, folhas, raízes.

\begin{abstract}
This study evaluated the morphological development of Carpetgrass (Axonopus affinis), Tifton 419 (Cynodon dactylon $\mathrm{x}$ C. transvaalensis) and Emerald (Zoysia sp.) turfgrasses grown in greenhouse and harvested at 97, 118, 146, 174, 202,230 and 258 days old. Tifton 419 showed the largest stolons $(83.3 \mathrm{~cm})$, height $(23.6 \mathrm{~cm})$ and leaf number $\left(12-24 \mathrm{~cm}^{-1}\right.$ stolon); leaves measured $6.7 \mathrm{~cm}$ x $1.9 \mathrm{~mm}$ (fine texture). Carpetgrass stolons reached on average $58.3 \mathrm{~cm}$ and were thicker $(2.5 \mathrm{~cm})$, with 2-4 leaf $\mathrm{cm}^{-1}$; their leaves measured $10.9 \mathrm{~cm} \times 12.3 \mathrm{~mm}$ (coarse texture) and the maximum height of the plant was $13 \mathrm{~cm}$. The Emerald presented the lowest height $(10 \mathrm{~cm})$, stolon length $(45 \mathrm{~cm})$, leaf number ( 7 leaves $\left.\mathrm{cm} \mathrm{stolon}^{-1}\right)$; their leaves measured $6.2 \mathrm{~cm} \mathrm{x} 3.7$ mm (medium texture). The dry matter accumulation ( $\mathrm{mg} \mathrm{plant}^{-1}$ ) reached 12,100 (Carpetgrass), 8,700 (Tifton 419) and 3,500 (Emerald), with root:shoot relation of $0.33,0.15$ and 0.19 , respectively. The distinct morphologic characteristics of the grasses may promote its use for different purposes.
\end{abstract}

Index terms: Axonopus, Cynodon, Zoysia, stolon, leaves, roots.

(Recebido em 15 de janeiro de 2009 e aprovado em 9 de março de 2010)

\section{INTRODUÇÃO}

No Brasil, as principais gramíneas para a formação de jardins pertencem aos gêneros Axonopus, Cynodon, Stenotaphrum e Zoysia. Em Axonopus, destacam-se pela tolerância ao frio, a grama-tapete ou São Carlos (A. affinis Chase) e a grama sempre-verde ou curitibana [A. compressus (Sw.) P. Beauv.] Suas diferenças mais marcantes para fins de identificação é a prefoliação, que na primeira é conduplicada e, na segunda, convoluta.

As espécies de Zoysia são oriundas da China, Japão e sudeste da Ásia. Em nível mundial, as principais representantes do gênero para fins esportivos e ornamentais são Z. japonica Steud., Z. matrella (L.) Merrill e Z. pacifica (Goudswaard) M. Hotta \& Kuroki, que diferem quanto à textura das folhas, de mais grosseira para mais fina, respectivamente. No entanto, o desenvolvimento de cruzamentos interespecíficos no gênero resultou em diversos híbridos, o que torna difícil a identificação e a denominação das cultivares encontradas no comércio. No Brasil, são comumente denominadas de grama-esmeralda ou grama-japonesa e, em geral, identificadas cientificamente como Z. japonica. Recentemente, Anderson (2000) e Shouliang \& Phillips (2006) estabeleceram chaves taxonômicas que permitem a identificação dos principais representantes do gênero, mas para cultivares essa tarefa é difícil, pois os híbridos possuem caracteres de mais de duas espécies. O que é denominada de grama-esmeralda no Brasil não é a cultivar Emerald desenvolvida nos Estados Unidos. Com base nas chaves taxonômicas (Anderson, 2008; Shouliang \& Phillips, 2006), é possível que seja um híbrido de Z. japonica $\mathrm{x} Z$. matrella. Da primeira, a grama-esmeralda

${ }^{1}$ Universidade de Passo Fundo/UPF - Avenida Sete de Setembro - 40 - Cx. P. 611 - 99010-120 - Passo Fundo, RS - cleusa@somasistemas.com.br ${ }^{2}$ Universidade de Passo Fundo/UPF - Passo Fundo, RS 
apresenta similaridade quanto ao comprimento do pedicelo e largura de folha. Os demais caracteres, como tamanho e forma da espigueta, comprimento do entrenó, posição das folhas, relação largura x comprimento da espigueta correspondem à descrição de Z. matrella.

Entre as cultivares de Cynodon, destaca-se a cv. Tifton 419 (Burton \& Hanna, 1985), resultante do cruzamento de Cynodon dactylon (L.) Pers. com C. transvaalensis Burtt Davy. Caracteriza-se pela textura fina e formação de uma camada de material morto, conhecido como thatch ou colchão, o que a confunde facilmente com Zoysia matrella. Desenvolve-se bem sob elevadas temperaturas, é tolerante à seca, mas pouco tolerante ao frio.

$\mathrm{O}$ fato de plantas ornamentais terem sua importância pouco reconhecida pelas instituições de pesquisa no país leva à escassez de informações técnicas, acarretando generalização de soluções e recomendações sem base científica. Com intuito de disponibilizar novas informações sobre as principais gramas ornamentais utilizadas no Brasil, subsidiar a escolha das espécies e práticas de manejo, neste estudo, avaliou-se o desenvolvimento morfológico das gramas esmeralda, São Carlos e Tifton 419.

\section{MATERIAL E MÉTODOS}

$\mathrm{O}$ estudo foi realizado em Passo Fundo, entre março e novembro de 2007, na região do Planalto Médio do Rio Grande do Sul, a $28^{\circ} 15^{\prime}$ 'S, 52 $24^{\circ}$ "W e $687 \mathrm{~m}$ de altitude. O clima é temperado úmido, com temperatura média anual de $17,5^{\circ} \mathrm{C}$, variando de $13,2^{\circ} \mathrm{C}$ a $23,6^{\circ} \mathrm{C}$, considerando as médias normais entre 1961 e 1990 (Empresa Brasileira de
Pesquisa Agropecuária - Embrapa, 2009). As plantas foram cultivadas em casa de vegetação, constituída de cobertura de plástico transparente e paredes laterais de tela do tipo clarite, onde foram registradas as temperaturas ocorridas durante o período experimental (Figura 1).

$\mathrm{O}$ trabalho constou de um bifatorial (espécie $\mathrm{x}$ idade) e os tratamentos foram alocados em delineamento de blocos casualizados, com três repetições. As gramas Esmeralda, São Carlos e Tifton 419 foram cultivadas durante 258 dias, nos quais foram avaliadas em sete idades, mediante colheitas destrutivas: 97, 118, 146, 174, 202, 230 e 258 dias de idade. No Herbário da Universidade de Passo Fundo (RSPF), encontram-se tombados exemplares das espécies acima referidas (RSPF 11588, 11589, 11590, 11591, 11592, 11593).

As unidades experimentais foram constituídas de floreiras plásticas ( $14 \mathrm{~cm} \mathrm{x} 44 \mathrm{~cm}$ ), com capacidade para $9 \mathrm{~kg}$ de substrato, que constou de um solo oriundo de área de lavoura, do tipo latossolo, com os seguintes atributos: argila $35 \% ; \mathrm{pH}=5,7 ; \mathrm{pH} \mathrm{SMP}=6,4 ; \mathrm{P}=53 \mathrm{mg} \mathrm{dm}^{-3} ; \mathrm{K}=78,1 \mathrm{mg} \mathrm{dm}^{-3}$; $\mathrm{Al}=0 \mathrm{cmol} \mathrm{dm}{ }^{-3} ; \mathrm{Ca}=5,8 \mathrm{cmol} \mathrm{dm}^{-3} ; \mathrm{Mg}=3,0 \mathrm{cmol} \mathrm{dm}^{-3} ; \mathrm{H}+$ $\mathrm{Al}=2,8 \mathrm{cmol} \mathrm{dm}^{-3} ; \mathrm{CTC}=13,6 \mathrm{cmol} \mathrm{dm}^{-3} ;$ M.O. $=3,7 \%$; Saturação de bases= $80 \% ; \mathrm{Al}=0 \% ; \mathrm{K}=14,7 \%$. Em 16/03/07, foram transplantadas do campo para floreira duas mudas contendo três nós. Mensalmente, foi aplicado $1 \mathrm{~g}$ de Nitrabor $(\mathrm{N}=15,5 \% ; \mathrm{Ca}=19 \% ; \mathrm{B}=0,3 \%)$ diluído em $200 \mathrm{~mL}$ de água, em cada unidade experimental. As colheitas ocorreram entre 21/06 e 29/11 de 2007.

As plantas foram avaliadas por meio de medidas lineares, de contagem e de peso (Benincasa, 2003). No momento da colheita, foram tomadas as medidas relativas à altura das plantas, da base até a inflexão da maior folha.

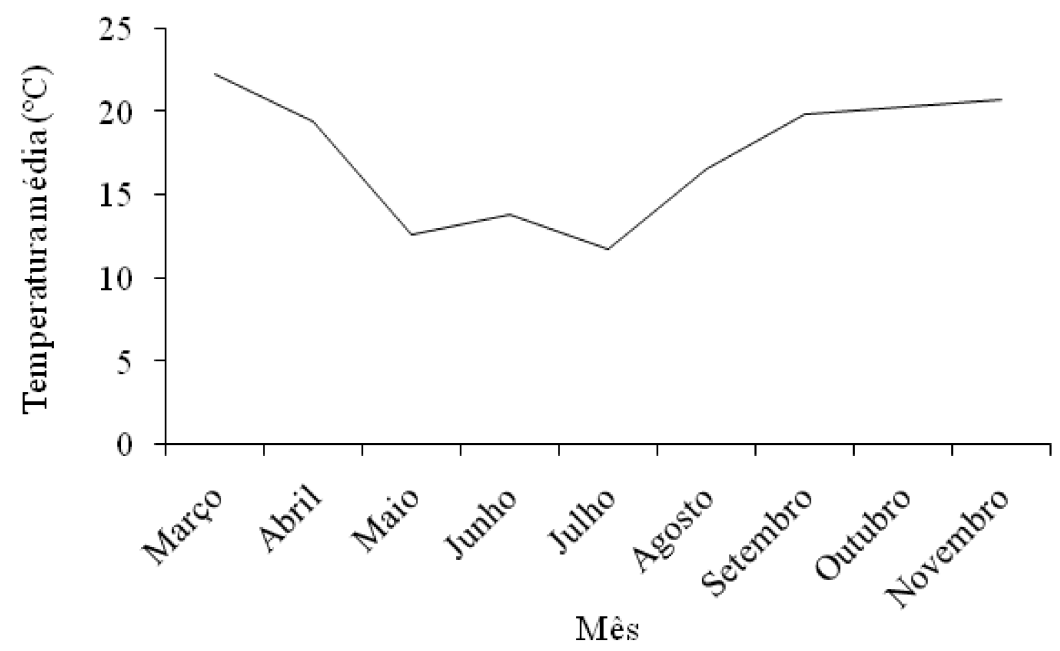

Figura 1 - Temperaturas médias registrada na casa-de-vegetação no período de crescimento das gramas, 2007. 
Posteriormente, as plantas foram retiradas das floreiras, lavadas em água corrente e levadas ao laboratório. O estolão mais longo, oriundo da planta mais vigorosa, foi avaliado quanto ao comprimento, espessura (diâmetro do segundo entrenó) e número de folhas. A partir desses dados, foi calculado o número específico de folhas, pela razão do número de folhas e comprimento de estolão. Três folhas totalmente expandidas foram medidas quanto ao comprimento e largura. Em seguida, nas duas plantas, foram separados os caules + folhas e as raízes, que, após pesagem, foram levados à estufa à $60^{\circ} \mathrm{C}$ até peso constante, quando, então, foram pesadas novamente, a fim de determinar o acúmulo de matéria seca (MS) das partes aéreas e subterrânea.

Os resultados foram submetidos à análise da variância e as médias foram comparadas pelo teste de Tukey a 5\% de significância. Para a avaliação do efeito da idade foi realizada análise de regressão em função da idade das plantas, caracterizada pelo número de dias após o transplante das mudas para as floreiras.

\section{RESULTADOS E DISCUSSÃO}

A altura das plantas aumentou linearmente nas três espécies, mas com distintas grandezas (Figura 2). A partir do final do inverno, as plantas exibiram maior crescimento, em virtude da elevação das temperaturas (Figura 1).

As espécies estudadas são estivais e sua faixa térmica preferencial está entre $27^{\circ} \mathrm{C}$ e $35^{\circ} \mathrm{C}$ (Beard, 1973), sendo que, para as bermudas, temperaturas abaixo de $12^{\circ} \mathrm{C}$ reduzem rapidamente a taxa de crescimento e o desenvolvimento (Buchanam et al., 2000). Esse híbrido exibiu a maior taxa de crescimento em altura, por possuir afilhos eretos e mais longos, formados ao longo dos estolões. Nas demais, os afilhos mostraram-se curtos e com pouco alongamento dos entrenós. Aos 258 dias de idade, as gramas Esmeralda $(10 \mathrm{~cm})$ e São Carlos $(15 \mathrm{~cm})$ foram similares quanto à altura e inferiores à Tifton $419(23,6 \mathrm{~cm})$.

O maior tamanho de folhas foi observado na São Carlos (Tabela 1), com comprimento $74 \%$ e $62 \%$ maior que a Tifton 419 e a esmeralda, respectivamente. Na largura, a relação entre essa espécie e as demais foi ainda

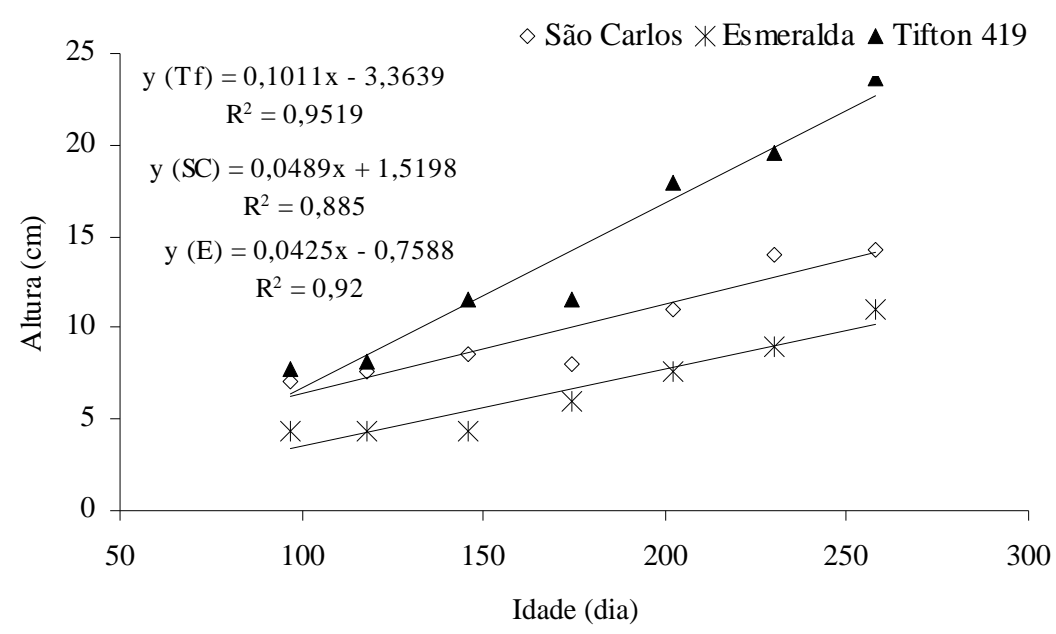

Figura 2 - Altura das gramas São Carlos, Esmeralda e Tifton 419 em função de dias de crescimento.

Tabela 1 - Características morfológicas das gramas São Carlos, Esmeralda e Tifton 419, na média de idade.

\begin{tabular}{lccc}
\hline Caractere & \multicolumn{3}{c}{ Gramas } \\
\cline { 2 - 4 } & São Carlos & Esmeralda & Tifton 419 \\
\hline Comprimento de folha $(\mathrm{mm})$ & $109 \mathrm{~A}$ & $62 \mathrm{~B}$ & $67 \mathrm{~B}$ \\
Largura de folha (mm) & $12,3 \mathrm{~A}$ & $3,7 \mathrm{~B}$ & $1,9 \mathrm{C}$ \\
Espessura de estolão $(\mathrm{mm})$ & $2,5 \mathrm{~A}$ & $1,1 \mathrm{~B}$ & $0,9 \mathrm{~B}$ \\
Número de nós/estolão & $10,0 \mathrm{AB}$ & $6,5 \mathrm{~B}$ & $11,8 \mathrm{~A}$ \\
Comprimento de entrenó $(\mathrm{mm})$ & $29 \mathrm{~A}$ & $18 \mathrm{~B}$ & $30 \mathrm{~A}$ \\
\hline
\end{tabular}

Médias seguidas de mesma letra na linha não diferem pelo teste de Tukey a 5\% de significância. 
mais evidente, com superioridade entre $321 \%$ (esmeralda) e $546 \%$ (Tifton 419). Esse caractere é importante para o reconhecimento das espécies no campo. No entanto, em virtude das variedades de formas nativas e/ou melhoradas, outros caracteres são necessários para sua identificação. Nogueira et al. (1999) apontaram para a probabilidade de confundir a Santo Agostinho com a São Carlos, em virtude da variedade de tipos morfológicos dessa última. Porém, quando ocorre florescimento, as inflorescências são distintas e não há problema para serem reconhecidas.

Segundo Beard (1973), ocorrem grandes variações morfológicas entre as espécies, como textura, largura e comprimento da folha, que diferenciam, também, as cultivares. Além das variações intraespecíficas, Murdoch et al. (1998) afirmaram que a textura do gramado também pode ser alterada com a frequência e a intensidade dos cortes, sendo que, quanto mais frequentes e severos, mais fino será o gramado. Dentre as espécies estudadas, a cv. Tifton 419 é a que possui as folhas mais estreitas, o que atribui ao seu gramado a classificação de textura fina. Um dos motivos para a impossibilidade da grama-esmeralda ser a cultivar Emerald é a largura da folha, que na cultivar americana é de 0,5 mm (Forbes, 1955) e no material cultivado no Brasil é de aproximadamente 3,7 $\mathrm{mm}$ (Tabela 1).

Os estolões das gramas esmeralda e Tifton 419 foram semelhantes quanto à espessura. A grama São Carlos apresentou estolões com mais do que o dobro de espessura dessas espécies, o que sugere maior durabilidade. Talvez, essa característica seja o motivo do forte arraigamento dos seus estolões na superfície do solo, conforme enfatizado por Nascimento et al. (1973). As espécies mostraram a mesma tendência e grandeza quanto ao número de nós e comprimento dos entrenós (Tabela 1, Figura 3). Quanto maior o número de nós, maior o potencial de formação de folhas, afilhos e/ou novos estolões, pois são sítios meristemáticos. Sua importância também está atrelada ao fato de que são regiões de formação de raízes adventícias, capazes de aumentar a fixação dos estolões no solo e de aumentar a área de absorção de nutrientes no solo.

As gramas Tifton $419(83,3 \mathrm{~cm})$ e São Carlos $(58,3 \mathrm{~cm})$ mostraram maiores estolões em relação à Esmeralda $(45 \mathrm{~cm})$, indicando maior capacidade de mobilidade e de colonização de novas partes áreas (Figura 4). A maior ou menor capacidade de estabelecimento de gramas estoloníferas é dependente desse atributo. Segundo Patton et al. (2007), genótipos de Zoysia spp. que alocam mais matéria seca para estolões e rizomas, ao invés de folhas, se estabelecem mais rapidamente.

A maior produção de folhas ocorreu na Tifton 419, sem haver diferença entre as demais espécies (Figura 5). Kim \& Beard (1988) obtiveram maior produção de folhas na cv. Emerald $\left(7.550 .10^{3} \mathrm{~m}^{-2}\right)$ em relação ao Tifton $419\left(4.560 .10^{3} \mathrm{~m}^{-2}\right)$. Neste estudo, a superioridade da Tifton 419 foi atribuída ao tamanho dos estolões, mais longos, e aos afilhos aéreos, similar à espécie Z. matrella, com a qual é confundida. Esse híbrido forma um dossel vegetativo espesso, proveniente dos afilhos eretos e do grande número de folhas. Como consequência, seus gramados exigem maiores cuidados na manutenção, com cortes frequentes para evitar a formação excessiva do thacht (Hensley et al., 1996).

As gramas mostraram tendência quadrática de acúmulo de MS (Figura 6), com pequenos aumentos nas quatro primeiras colheitas, em virtude das temperaturas mais baixas. A grama Tifton 419 é considerada fortemente estacional, com baixas produções no outono-inverno, pois é tipicamente tropical (Unruh et al., 1996). Com o aumento das temperaturas, a resposta das gramas foi expressiva, especialmente para esse híbrido e para a São Carlos, com menores taxas de crescimento para a grama esmeralda.

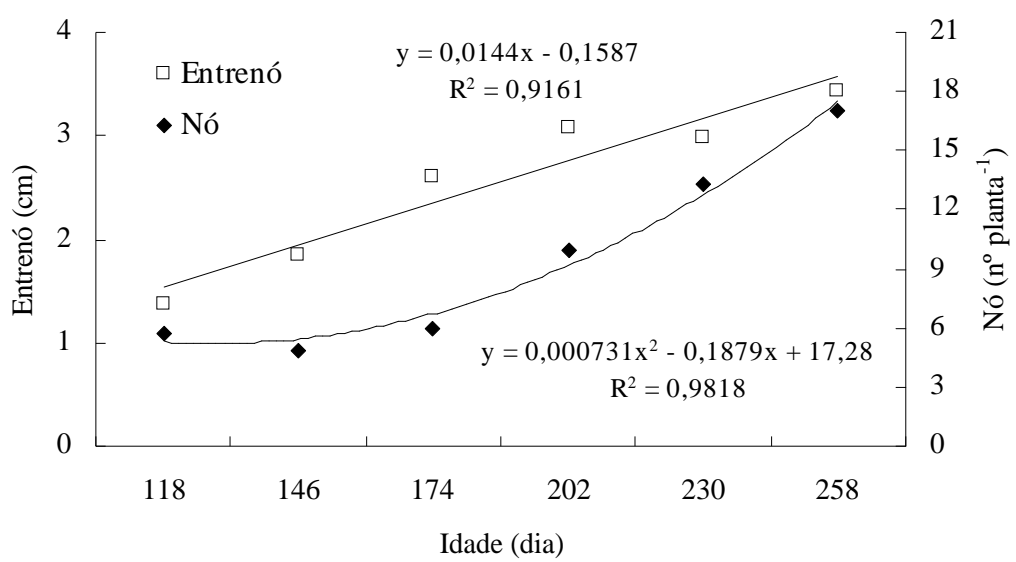

Figura 3 - Comprimento médio de entrenós e número de estolões em função de dias de crescimento, na média de espécie. 


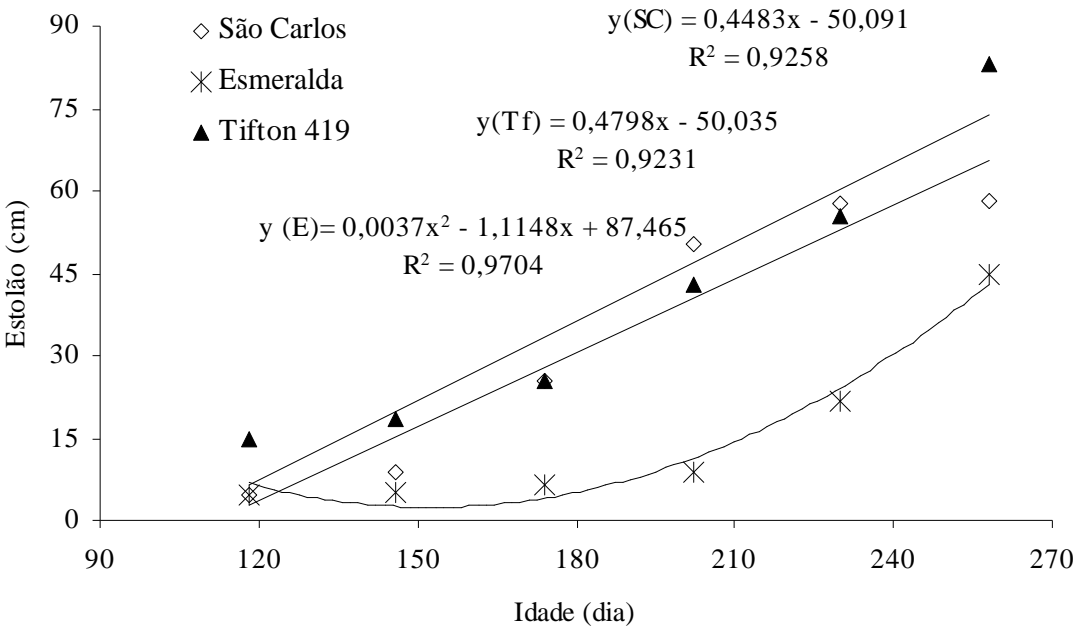

Figura 4 - Comprimento do estolão das gramas São Carlos, Esmeralda e Tifton 419 em função de ias de crescimento.

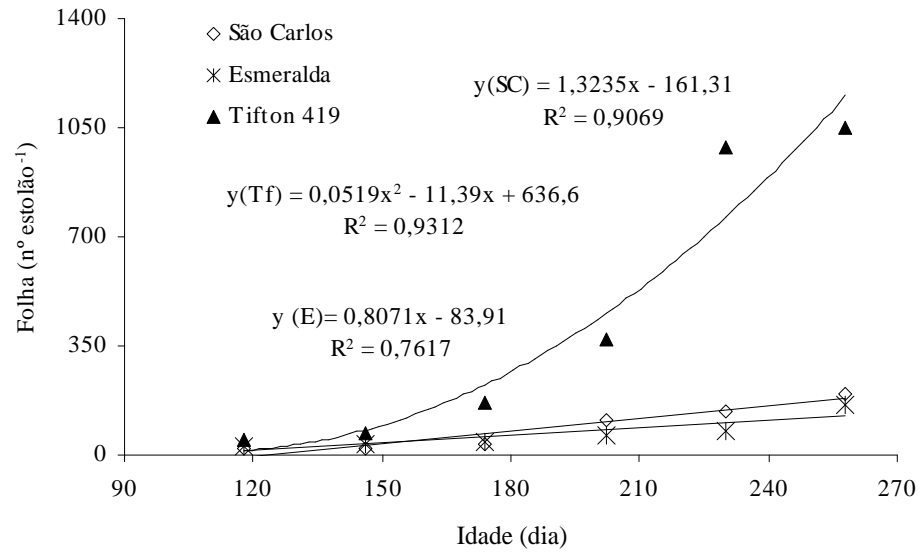

Figura 5 - Número de folhas nas gramas São Carlos, Esmeralda e Tifton 419 em função de dias de crescimento.

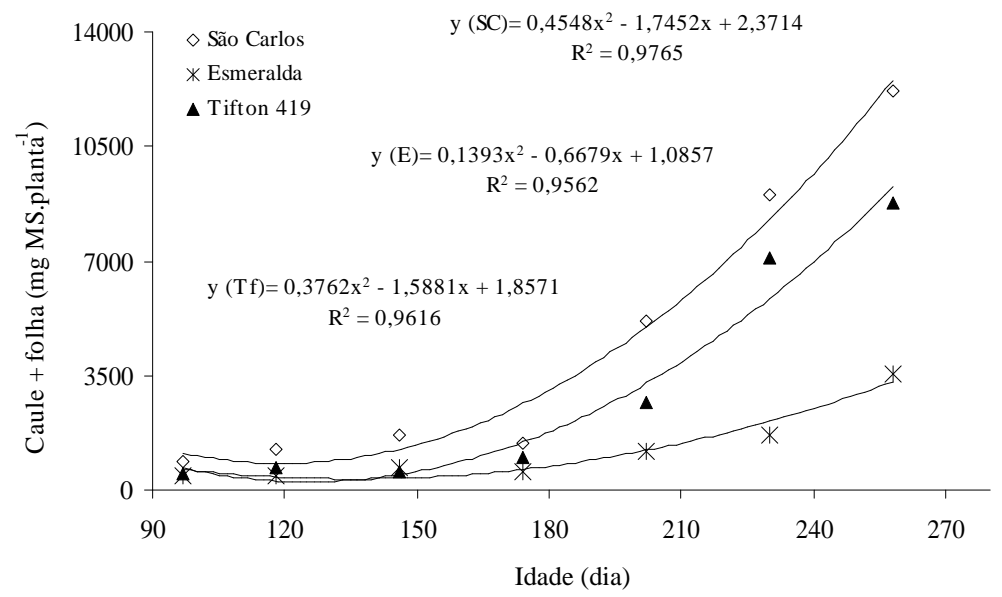

Figura 6 - Acúmulo de matéria seca de caules+folhas das gramas São Carlos, Esmeralda e Tifton 419, em função de dias de crescimento. 
Apesar da similaridade dessas espécies quanto à magnitude da matéria seca acumulada, os componentes da produção foram distintos. A Tifton 419 tem como características o elevado número de folhas, formadas verticalmente ao longo dos afilhos, ao passo que na São Carlos, as folhas têm maior tamanho e são formadas ao longo dos estolões, em curtos afilhos, com no máximo três folhas. Essas diferenças se refletem na aparência e manutenção dos seus gramados e reforçam a necessidade de cortes severos e frequentes na Tifton 419, ao contrário do que normalmente é realizado em gramados residenciais, em que apenas a altura é tomada como indicativo de cortes. Assim, na grama São Carlos, a altura do gramado pode ser um bom indicativo para cortes de manutenção, ao contrário da Tifton 419.

Os gramados formados por Zoysia spp., apesar da baixa altura, podem formar expressiva quantidade de matéria seca. Em Kinkasan Island, no Japão, as pastagens nativas de Z. japonica são altamente produtivas, em virtude dos vigorosos estolões e à produção de afilhos (Ito \& Takatsuki, 2005). Neste estudo, a grama esmeralda, em consequência de seu padrão morfogênico, apresentou acúmulo de MS inferior às demais, sugerindo maior facilidade de manutenção. Porém, em relação à matéria seca de raízes, foi similar à Tifton 419 (Figura 7).

A grama São Carlos manifestou maior acúmulo de MS nas raízes, pressupondo ser um forte dreno de fotoassimilados (Figura 8). Segundo Grzesiak et al. (2002), a relação entre raiz e parte aérea (RPA) é de vital importância para o balanço hídrico das plantas e acredita-se que as espécies com maior relação RPA sejam mais tolerantes à seca. No entanto, segundo Kim \& Beard (1988), Zoysia spp. e Cynodon spp. são mais tolerantes à seca do que Axonopus spp., em virtude de caracteres fisiológicos, anatômicos e do tipo de dossel, que ocasionam baixas taxas de evapotranspiração.

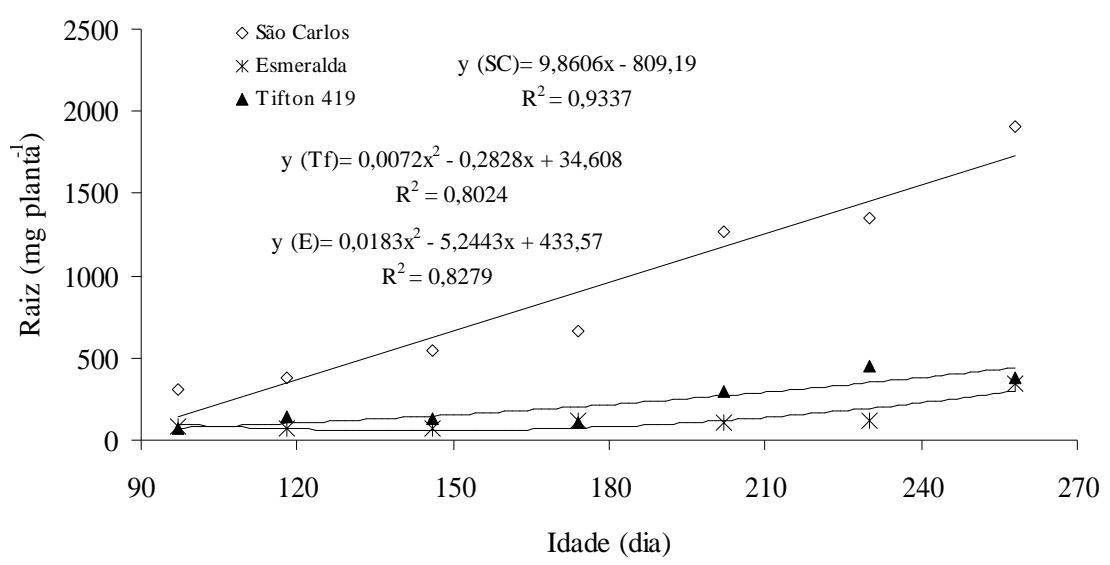

Figura 7 - Acúmulo de matéria seca de raízes das gramas São Carlos, Esmeralda e Tifton 419 em função de dias de crescimento.

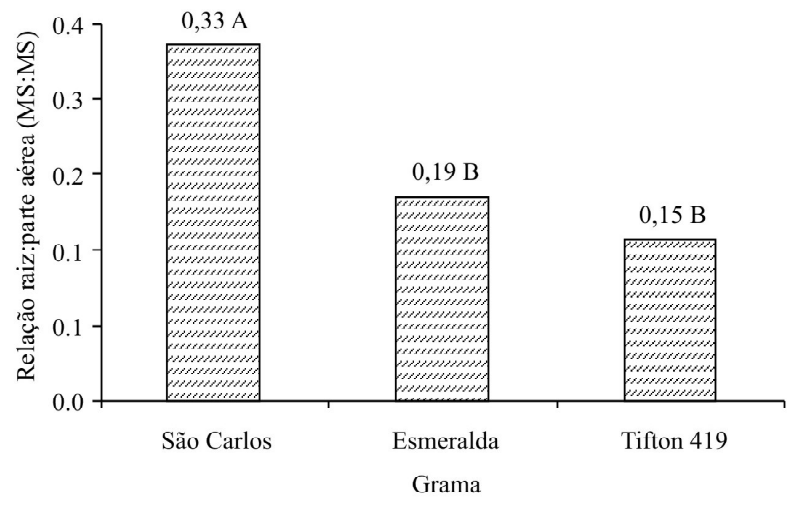

Figura 8 - Relação raiz:parte aérea das gramas São Carlos, Esmeralda e Tifton 419 na média das idades, durante 258 dias de crescimento. Letras distintas sobre os histogramas acusam diferença significativa pelo teste de Tukey a $5 \%$ de significância. 


\section{CONCLUSÕES}

As gramas Tifton 419, Esmeralda e São Carlos são de textura fina, média e grossa, respectivamente. As distintas características morfológicas das gramas São Carlos (maiores tamanho de folha, espessura de estolão e relação raiz:parte aérea), Tifton 410 (menor largura de folha, maior número de folhas e comprimento de afilhos) e Esmeralda (menor altura e comprimento de entrenós) podem subsidiar sua escolha para finalidades paisagísticas, ambientais e esportivas.

\section{REFERÊNCIAS BIBLIOGRÁFICAS}

ANDERSON, S.J. Taxonomy of Zoysia (Poaceae): morphological and molecular variation. Tracy Herbarium: Department of Rangeland Ecology and Management, 2008. Disponível em: <http// botany2000>. Acesso em: 25 jun. 2008.

ANDERSON, S.J. Zoysia Willd. In: BARKWORTH, M.E. (Ed.). Manual of grasses for North America and Flora North America of Mexico. Utah: University of Utah, 2008. Disponível em: <http//herbarium.usu.edu〉. Acesso em: 1 jul. 2008.

BEARD, J.B. Turfgrass: science and culture. New Jersey: Prentice-Hall, 1973. 658p.

BENINCASA, M.M.P. Análise de crescimento de plantas: noções básicas. Jaboticabal: Funesp, 2003. 41p.

BUCHANAN, B.B.; GRUISSEM, W.; JONES, R.L.

Biochemistry and molecular biology of plants. Rockville: Americam Society of Plant Physiologists, 2000. 1367p.

BURTON, G.; HANNA, W. Bermudagrass. In: HEATH, M.; BARNES, R.; MATCALFE, E. Forages the science of grassland agriculture. Iowa: Ames, 1985. 643p.

EMPRESA BRASILEIRA DE PESQUISA AGROPECUÁRIA. Normas climatológicas: 1961-1990. Disponível em: <http:// www.cnpt.embrapa.br/pesquisa/agromet/app/principal// tnormais.php>. Acesso em: 20 nov. 2009.

FORBES, I.; ROBINSON, B.P.; LATHAN, J.M. Emerald Zoysia: an improved hybrid lawn grass for the South. USGA Journal and Turf Management, Georgia, p.23-26, 1955.
HENSLEY, D.; YOGI, J.; TAVARES, J.; MURDOCH, C. Common lawn grasses for Hawaii. Manoa: CTAHR, 1996. (Instant Informative Series, 22).

ITO, T.Y.; TAKATSUKI, S. Relationship between a high density of sika deer and productivity of the short-grass (Zoysia japonica) community: a case study on Kinkazan Island, northern Japan. Ecological Research, Sendai, v.20, p.573-579, 2005.

KIM, K.S.; BEARD, J.B. Comparative turfgrass evapotranspiration rates and associated plant morphological characteristics. Crop Science, Madison, v.28, p.328-331, 1988.

NASCIMENTO, J.A.L.; FREITAS, E.A.G.; DUARTE, C.M.L. A grama missioneira no planalto Catarinense. Florianópolis: Empresa Catarinense de Pesquisa Agropecuária, 1973. (Boletim técnico, 52).

NOGUEIRA, M.C.L.; ROSITO, J.M.; SCHIRMER, A.G. Identificação de Paspalum notatum Fluegge e Axonopus affinis Chase através da análise de fragmentos foliares. Ciência Rural, Santa Maria, v.29, n.1, p.27-31, 1999.

MURDOCH, C.; DEPUTY, J.; HENSLEY, D.; TAVARES, J. Adaptation of turfgrasses in Hawaii. Turf Management, Manoa, v.4, p.3-6, 1998. Disponível em: <http:// 'www.ctahr.hawaii.edu/oc/freepubs/pdf/TM-4.pdf خ. Acesso em: 20 jul. 2008.

PATTON, A.J.; VOLENEC, J.J.; REICHER, Z.J. Stolon growth and dry matter partitioning explain differences in zoysiagrass establishment rates. Crop Science, Madison, v.47, n.1, p.237-1245, 2007.

SHOULIANG, C.; PHILLIPS, S.M. Zoysia Willdenow, Ges. Naturf. Flora of China, Berlin, v.22, p.496-498, 2006.

UNRUH, J.B.; GAUSSOIN, R.E.; WIEST, S.C. Basal growth temperatures and growth rate constants of warmseason turfgrass species. Crop Science, Madison, v.36, p.997-999, 1996. 